\title{
EFFICIENCY OF INTEGRATED ULTRASONIC AND ANAEROBIC DIGESTION OF OIL REFINERY WASTEWATER SLUDGE
}

\author{
ALMASI A. ${ }^{1}$ \\ MOSAVI A. ${ }^{2}$ \\ MOHAMMADI M. ${ }^{1}$ \\ AZEMNIA S., ${ }^{2}$ \\ GODINI K. ${ }^{3}$ \\ ZAREI A. ${ }^{4}$ \\ MOHAMMADI S. ${ }^{2}$ \\ SALEH E. ${ }^{5}$
}

\author{
${ }^{1}$ Department of Environmental Health Engineering \\ Public Health School \\ Social Development and Health Promotion Research Center \\ Kermanshah University of Medical Science, Iran \\ ${ }^{2}$ Department of Environmental Health Engineering \\ Public Health School \\ Kermanshah University of Medical Science, Iran \\ ${ }^{3}$ Department of Environmental Health Engineering \\ Public Health School \\ Hamadan University of Medical Sciences, Iran \\ ${ }^{4}$ Department of Environmental Health Engineering \\ Public Health School \\ Shahid Beheshti University of Medical Sciences, Tehran, Iran \\ ${ }^{5}$ Department of Bio Statistic, Public Health School \\ Kermanshah University of Medical Sciences, Iran
}

Received: 07/02/2016

Accepted: 15/06/2016

Available online: 26/07/2016

*to whom all correspondence should be addressed: e-mail: somayeazemnia@gmail.com

\section{ABSTRACT}

The main effects of ultrasonic sludge are solubilization and release of organic components and biodegradability enhance of sludge by disrupting the physical, chemical and biological properties sludge. The objective of the current study was to determine the effect of ultrasound on anaerobic digestion of oil refinery sludge subjected to different pretreatments. A 300-ml anaerobic reactor was filled with 250 of the waste activated sludge and placed on a hot plate magnet for $41 \mathrm{~d}$. A vibrato bath $(40 \mathrm{kHz}, 100 \mathrm{~W})$ was used in $30 \mathrm{~min}$ and $60 \mathrm{~min}$ and three cycles of $15 \mathrm{~min}$. Mixed liquor suspended solids (MLSS)was ranged between $28100 \pm 282$ and $12000 \pm 642 \mathrm{mg} \mathrm{l}^{-1}$. The data were collected in a log phase condition. TSS, VSS, $\mathrm{TCOD}$ and $\mathrm{BOD}_{5}$ were measured following the standard methods. The combined reactor had the best performance in sludge digestion compared to anaerobic reactor with/ without ultrasonic pretreatment. Between two irradiation times ( 30 and $60 \mathrm{~min}$ ) and the same situation, 60 min ultrasonic pretreatment was found to be more effective. Ultrasonic pretreatment accelerated the digestion process. In this project, oil refinery sludge with industrial feature attained to log phase after 41 days.

Keywords: Ultrasonic, Anaerobic Digestion, Sludge, Oil Refinery

\section{Introduction}

Petroleum refineries use large quantities of water in extraction, desalting, and cooling processes, which generate waste streams, containing different petroleum compounds, and may be discharged to the refinery wastewater treatment plant (WWTP) (Misiti et al., 2013).

Almasi A., Mosavi A., Mohammadi M., Azemnia S., Godini K., Zarei A., Mohammadi S. and Saleh E. (2016), Efficiency of integrated ultrasonic and anaerobic digestion of oil refinery wastewater sludge, Global NEST Journal, 18(4), 771-777. 
Because of strict environmental standards, more advanced levels of wastewater treatment measures are required to meet the effluents standard limits; this leads to greater energy use and sludge production at WWTPs (Xie et al., 2009). In WWTPs sewage and sludge are dealt with and well treated (Apul and Sanin, 2010). Treatment and disposal of excess sludge can account for $25-65 \%$ of total plant operation costs (Cheng and Hong, 2013). It is thus essential to develop processes to reduce sludge quantity. One of the most interesting processes is anaerobic digestion (Kocyig and Ugurlu, 2015), which has widely been used to treat various industrial wastewaters for the stabilization of a large fraction of the organic matter entering the plant (Braguglia et al., 2012; Cesaro and Belgiorno, 2013; Şahinkaya and Sevimli, 2013). The efficiency of anaerobic digestion can be greatly enhanced by using physical and/or chemical pretreatment processes improving the rate of hydrolysis steps (Braguglia et al., 2012; Cesaro and Belgiorno, 2013; Şahinkaya and Sevimli, 2013). Recently, waste activated sludge (WAS) pretreatments like thermal, alkaline, ultrasonic, and ozone oxidation methods have been applied to improve hydrolysis and anaerobic digestion performance, and a range of acceptable results have been reported to date (Braguglia et al., 2012; Muz et al., 2014; Salsabil et al., 2010; Naddeo et al.,2014). The term "ultrasonic" is generally taken to mean that the "frequency" of the wave is greater than the upper limit of human hearing (usually taken to be $20 \mathrm{kHz}$ ) (Erden et al., 2010). The main effects of ultrasonic sludge are solubilizing and releasing of organic components, by which the biodegradability of them is enhanced via disrupting the physical, chemical and biological properties of the sludge (Pilli et al., 2011; Dewil et al., 2006)., Hydraulic retention time of anaerobic digester can be shortened by using an ultrasonic pretreatment (Şahinkaya and Sevimli, 2013). In noted method, oxidation by hydroxyl radical can break down the toxic chemical compounds like cyanide, oil, phenols, benzene, sulfide, ammonia and heavy metals that are present in refinery effluents. The rapid collapse and expansion of the micro-bubbles cause localized high-temperature and highpressure gradients in the liquid phase, which ruptures cell membrane, releasing intercellular matter in the bulk solution (Rocha et al., 2012; Rahmani et al., 2013). The aim of this research was to investigate the effect of ultrasound on anaerobic digestion of oil refinery sludge subjected to different variables.

\section{Methods}

\subsection{Waste Activated Sludge (WAS) characteristics}

WAS for this experiment was taken from the return line of the sedimentation tank of the WWTP located in Kermanshah Oil Refinery, Iran. After passing the physical units and chemical processes (coagulation and flocculation), the refinery wastewater was transported to the biological treatment process. The activated sludge samples were kept at $2-4{ }^{\circ} \mathrm{C}$ to avoid unintended microbial reactions. The sludge had a mixed liquor suspended solid (MLSS): $30.7 \mathrm{~g} \mathrm{l}^{-1}$, mixed liquor volatile suspended solid (MLVSS): $21.3 \mathrm{~g} \mathrm{l}^{-1}$, total chemical oxygen demand (TCOD): $46.6 \mathrm{~g} \mathrm{l}^{-1}$ and $\mathrm{pH}$ : 7.9. $\mathrm{pH}$ was adjusted by adding alkali solution $\left(0.5 \mathrm{~mol} \mathrm{I}^{-1}\right.$ $\mathrm{NaHCO} 3$ and $0.5 \mathrm{~mol} \mathrm{I}^{-1} \mathrm{Na2CO}$ ) (Jin et al., 2015). In order to minimize random errors, each experiment was triplicated and the mean of them was used (Table 1).

Table 1. Characteristics of the inlet sludge.

\begin{tabular}{cccc}
\hline Parameter & Unit & Concentration 1 & Concentration 2 \\
\hline MLSS $_{\text {in }}$ & $\mathrm{mg} \mathrm{l}^{-1}$ & $282 \pm 28100$ & $642 \pm 12000$ \\
\hline $\mathrm{TCOD}^{-1}$ & $\mathrm{mg} \mathrm{l}^{-1}$ & $675 \pm 46683$ & $834 \pm 20808$ \\
\hline $\mathrm{mOD}_{5}$ & $\mathrm{mg} \mathrm{l}^{-1}$ & $238 \pm 10000$ & $808 \pm 4000$ \\
\hline $\mathrm{TSS}$ & $\mathrm{mg} \mathrm{l}^{-1}$ & $1188 \pm 30766$ & $760 \pm 15283$ \\
\hline $\mathrm{VSS}$ & $\mathrm{mg} \mathrm{l}^{-1}$ & $929 \pm 21366$ & $298 \pm 10658$ \\
\hline $\mathrm{pH}$ & $\mathrm{mg} \mathrm{l}^{-1}$ & $0.29 \pm 7.8$ & $0.29 \pm 7.8$ \\
\hline
\end{tabular}

\subsection{Anaerobic digester set-up}

To set up the anaerobic reactor, $250 \mathrm{ml}$ of WAS was poured into the batch reactor with a volume of 300 $\mathrm{ml}$ and was placed on a hot plate magnet (ALFA D500) in $38{ }^{\circ} \mathrm{C}$ under $200 \mathrm{rpm}$ shaking; necessary parameters like TSS, VSS and Total COD (TCOD) were monitored for up to $41 \mathrm{~d}$. The generated biogas was 
collected in calibrated glass cylinders containing deionized water acidified and was filled free space of each flask with pure $\mathrm{N}_{2}$.

\subsection{Ultrasonic irradiation pre-treatment}

A vibrate bath (DSA100-SK2) was used with an operating frequency of $40 \mathrm{kHz}$ and a supplied power of $100 \mathrm{~W}$. In the current study, four types of reactors were operated in mixed liquor suspended solids (MLSS) concentrations of $28100 \pm 282\left(\mathrm{mg} \mathrm{l}^{-1}\right)$ and $12000 \pm 642\left(\mathrm{mg} \mathrm{l}^{-1}\right)$. Reactor 1: anaerobic digestion, reactor 2: ultrasonic (US) pretreatment in $60 \mathrm{~min}$ irradiation, reactor 3: US pretreatment in 30 min irradiation, reactor 4: combined reactor (simultaneous irradiation along with an aerobic digestion), which was irradiated in three periods of $15 \mathrm{~min}$. As each sonication pretreatment, $250 \mathrm{~mL}$ of the wastewater was filled in a glass beaker without temperature adjustment (without cooling) and submerged into the ultrasonic bath. Data were collected in steady state conditions.

\subsection{Analytical methods}

The sludge samples were used directly for the measurement of TSS, VSS, TCOD, biological oxygen demand $\left(\mathrm{BOD}_{5}\right)$ and $\mathrm{MLSS}$. The $\mathrm{pH}$ and $\mathrm{COD}$ were measured by a pH meter (MADC, Swiss) and a TCOD meter (HACH NATOQUE), respectively. All chemicals were purchased from Merck Inc. (Germany). The noted parameters were measured according to the Standard Methods (Association et al., 2008).

\subsection{Performance assessment of the system}

Removal efficiency was evaluated according to Eq. (1):

$$
\text { Removal efficiency }(\%)=\left(\frac{\text { parameter value }(\mathrm{t} 0)-\text { parameter value }(\mathrm{tf})}{\text { Parameter value }(\mathrm{t} 0)}\right) \times 100
$$

\subsection{Statistical analysis}

Statistical analysis was performed using SPSS software aided (version 20.0, Chicago, IL) at the significant level of $95 \%$. The results have been presented as means \pm standard deviation. The obtained data were tested for normality by the Kolmogorov-Smirnov test and ttest was employed to reveal significant difference reactors in two MLSS concentrations.

\section{Results and discussion}

\subsection{Mesophilic Batch Anaerobic Reactor}

Due to the industrial nature and the presence of persistent contaminants with having biodegradability, a hydraulic retention time (HRT) of $41 \mathrm{~d}$ was exerted to digest organic solids in the sludge. The main objective of this study was to improve the bioavailability of particulate sludge material.

Table 2. Reactor performance in COD, TSS and VSS removal.

\begin{tabular}{ccccc}
\hline Reactor & MLSS & COD removal, \% & TSS removal, \% & VSS removal, \% \\
\hline \multirow{2}{*}{ Anaerobic digestion } & $28100 \pm 282$ & 80.9 & 52 & 50 \\
\cline { 2 - 5 } & $12000 \pm 642$ & 72.6 & 50 & 45 \\
\hline \multirow{2}{*}{ Ultrasonic (60 $\mathrm{min})$} & $28100 \pm 282$ & 82.3 & 61 & 60 \\
\cline { 2 - 5 } & $12000 \pm 642$ & 86 & 55 & 55 \\
\hline \multirow{2}{*}{ Ultrasonic (30 $\mathrm{min})$} & $28100 \pm 282$ & 80.3 & 56 & 55 \\
\cline { 2 - 5 } & $12000 \pm 642$ & 82.5 & 54 & 71 \\
\hline \multirow{2}{*}{ Combined reactor } & $28100 \pm 282$ & 88.4 & 79 & 66 \\
\cline { 2 - 5 } & $12000 \pm 642$ & 85.4 & 76 & \\
\hline
\end{tabular}


The COD/BOD5, is a parameter that measures the rate of biological degradation of biosolids. The COD/ BOD5 ratios in MLSS concentrations of 28100 and $12000 \mathrm{mg} \mathrm{l}^{-1}$ were 0.21 and 0.19 , respectively. These ratios were reached to 0.09 and 0.08 at the end of digestion.

The anaerobic reactor (control reactor) could decrease 80.9 and $72.6 \%$ of TCOD and 50 and $45 \%$ of VSS at MLSS $=28000$ and $12000 \mathrm{mg} \mathrm{l}^{-1}$, respectively.

Nosrati et al., (2011) studied mesophilic anaerobic digestion by a batch anaerobic reactor in 2011 they reported that TCOD and VSS were reduced from 70000 to $32000 \mathrm{mg} \mathrm{l}^{-1}$ and 45000 to $20000 \mathrm{mg} \mathrm{l}^{-1}$, respectively (Nosrati et al., 2011). Also, TCOD and VSS reduction (43 and 41\%) for a 20-day HRT was reported by El-Hadj et al., (2007).

In this study, VSS/TSS ratio of the inlet sludge to the anaerobic digester was 0.69. Consequently, due to the high efficiency of anaerobic digesters in this study compared to the studies mentioned can be attributed to high the VSS/TSS ratio.

\subsection{Ultrasound pretreatment}

According to Figs.1and 2, the VSS and TCOD of MLSS concentrations 28000 and $12000 \mathrm{mg} \mathrm{l}^{-1}$ in reactors \#2 and \# 3 were similar and the flow in the reactors reached a steady-state condition.

Dhar et al., (2012) reported that the greatest rate of increase in digestion process was observed after 30 min at $90{ }^{\circ} \mathrm{C}$ followed by $10000 \mathrm{~kJ} \mathrm{~kg}^{-1} \mathrm{TSS}$ for ultrasound pretreatment. Ultrasonic significantly improved VSS reduction by 29-38\% (Dhar et al., 2012). In this study, with increasing US exposure time, TCOD removal efficiency increased. Erden et al., (2010) claimed that with the increase of ultrasonic irradiation time from zero to $60 \mathrm{~min}$, soluble COD (SCOD) production rate has changed from 0 to $10000 \mathrm{mg} \mathrm{l}^{-1}$ (Erden et al., 2010). In other words, a longer contact time results in an increase in the amount of dissolved and biodegradable substances, which can be stabilized faster.

Şahinkaya and Sevimli examined a US pretreatment $(20 \mathrm{KHz}, 200 \mathrm{w}, \mathrm{t}=10 \mathrm{~min})$ and reported that TCOD removal efficiency was improved from 37.5 to $42.9 \%$ (Şahinkaya and Sevimli, 2013). The cause of a 5.2\% rise in this study, despite higher intensity, is due to low US exposure times.

In the control reactor, TSS was removed with a gradual slope, whereas in reactor 2\# there was a steeper slope and up to the first 6 days of digestion, most of removal happened. This illustrates the effect of ultrasonic waves on solubilization of sludge's solids that converts particles to smaller sizes (Cesaro and Belgiorno, 2013).

Most of TSS removal efficiency of reactor2\# has been at higher MLSS concentration (9\%) compared to the control reactor.

The performance of all reactors at MLSS $=12000 \mathrm{mg} \mathrm{l}^{-1}$ was statistically significant, considering the standard error reported in Table 2. Also, reactors $2 \#$ and $3 \#$ were different only in performance at MLSS $=28000 \mathrm{mg} \mathrm{l}^{-1}$. In fact, the calculated t-test statistic for comparing these two concentrations reflects that the means of the two groups are different, which should be accepted at $\alpha=0.05$.

At the 60 -min pretreatment and lower concentration, reduction of total solid increased slightly to $5 \%$. In fact, although the removal efficiency of TSS at a lower concentration is poor, the ultrasound pretreatment can be effective in anaerobic digester performance in comparison with the control reactor. Another study, in which the effect of ultrasound pretreatment on mesophilic and thermophilic anaerobic digestion was investigated, reported a $3 \%$ improvement in TSS removal (El-Hadj et al., 2007).

Solubilization of TSS is a sure parameter for predicting sludge volume decreasing improvement. Bougrier et al., (2006) have attained to 80 and $89 \%$ sludge volume reduction by using a US pretreatment (sludge retention time $(S R T)=7$ ).

In steady state condition, VSS variations marginally fluctuated lower than $5 \%$ illustrating that reactor $2 \#$ (at MLSS concentration: $28100 \mathrm{mg}^{-1}$ ) reached the steady state in $31 \mathrm{~d}$, whereas in control reactor it was 38 days from a digestion period. Pretreatment, due to hydrolyze acceleration and increase of soluble 
organic fraction, makes sludge digestion happen better and sooner than a control reactor (Braguglia et al., 2012).

Maximum removal efficiency $(60 \%)$ was observed in reactor $2 \#$, which shows a $9 \%$ improvement in comparison with the control reactor. By comparing the results of reactors $2 \#$ and $3 \#$, where the sludge was pre-treated at the same conditions, it was evident that mean difference was not statistically significant. In 60 min irradiation time, no effective removal of VSS was seen. Mohammadi et al., (2011) revealed that the reduction of sludge was affected by multiple factors including the energy supplied to sludge mass, the power used for wave generation, duration of wave usage, and percentage of sludge exposed to the waves (Mohammadi et al., 2011). Figs 1 and 2, demonstrate TCOD and VSS remaining trends in anaerobic digesters at a high concentration.

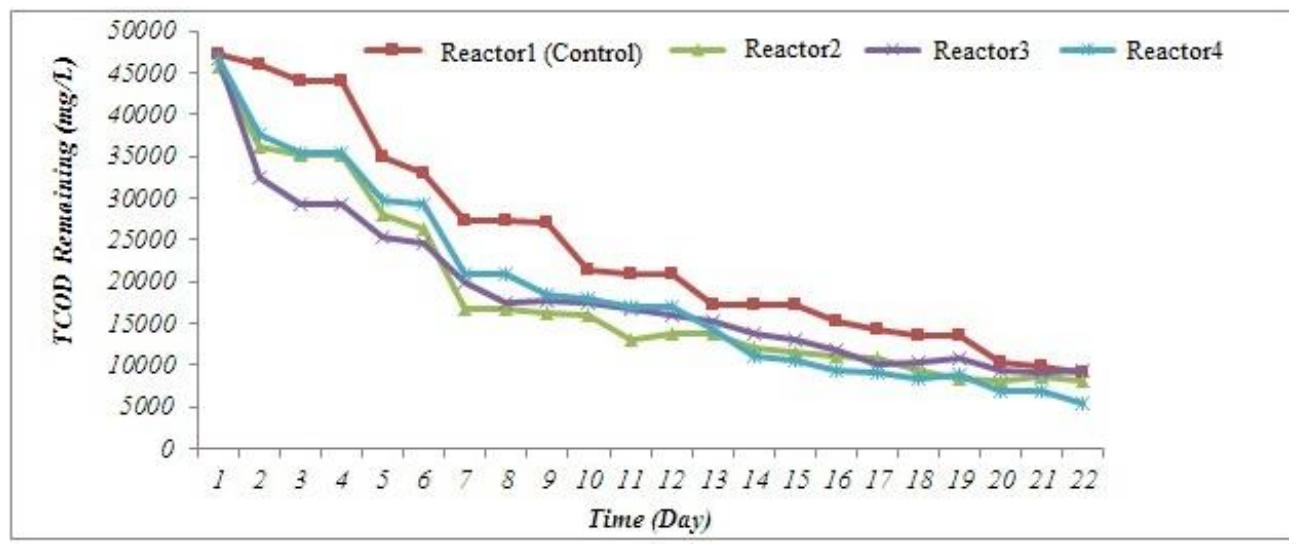

Figure 1. TCOD reduction in reactors: 1 (anaerobic digester), 2 (anaerobic digester $+60 \mathrm{~min}$ pretreatment), 3 (anaerobic digester+ 30 min pretreatment), 4 (combined reactor), MLSS $=28100 \mathrm{mg} \mathrm{l}^{-1}$

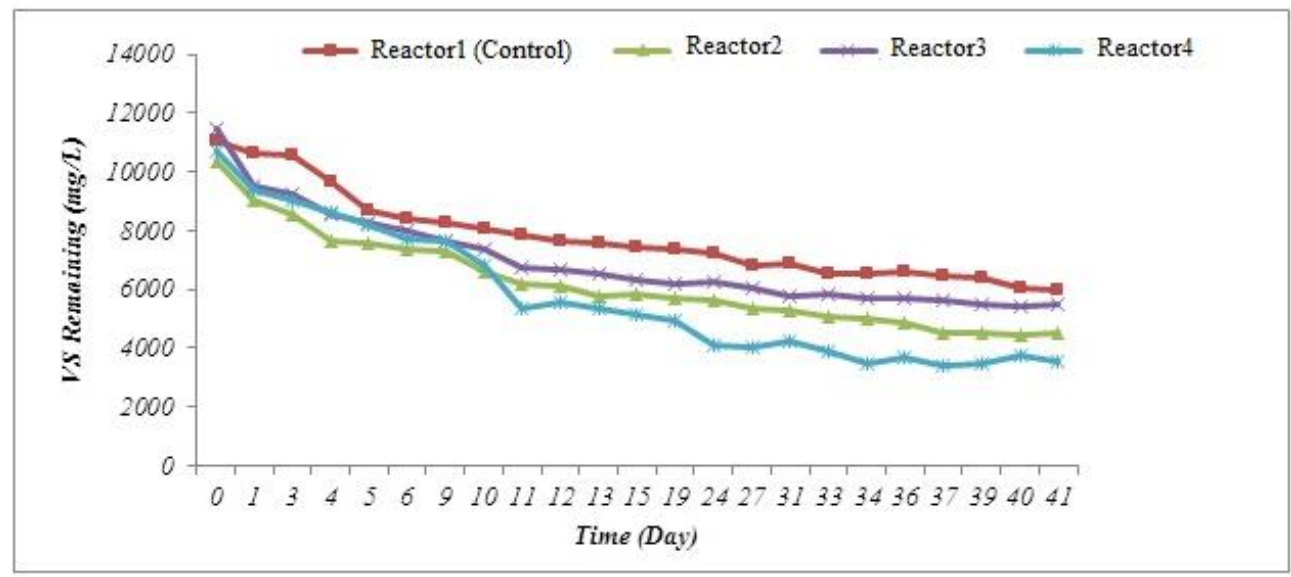

Figure 2. VSS reduction in reactor: 1 (anaerobic digester), 2 (anaerobic digester $+60 \mathrm{~min}$ pretreatment), 3 (anaerobic digester +30 min pretreatment), 4 (combined reactor) and MLSS $=28100 \mathrm{mg} \mathrm{l}^{-1}$

\subsection{Combined reactor (simultaneous irradiation \& digestion)}

In 2, 10 and $20 \mathrm{~d}$, reactor $4 \#$, despite of other reactors, had a better variation trend due to periodical irradiation and a considerable slope can be observed in the graphs. For example, the control reactor removed TSS with a moderate slope, whereas reactor $4 \#$ had a keen slope at the first $20 \mathrm{~d}$. In this study, maximum TCOD, TSS and VSS removal efficiency was obtained approximately $88.4,79$, and $71 \%$, respectively, and statistical analysis confirms the efficiency difference between combined reactors and other reactors ( $P$-Value $<0.05$ ). It is obvious that high concentration of biosolids lead to an increase in the performance of the combined reactor. Ma et al., (2012) reported the sludge pretreatment system by ultrasonic performed well and its TCOD removal efficiency was $7.9 \%$, which contributed to a sludge 
reduction of 2.1\% (Ma et al., 2012).However, in the present study, TCOD removal increased by 7.5 and $12.8 \%$, respectively, at two MLSS concentrations ( 28100 and $12000 \mathrm{mg} \mathrm{l}^{-1}$ ) due to the periodical irradiation (3 times \& $15 \mathrm{~min}$ ). The combined reactor had the best performance in sludge digestion compared to the anaerobic reactor with/ without the US pretreatment. Between two irradiation times ( 30 and $60 \mathrm{~min}$ ) and at the same situation, $60 \mathrm{~min}$ of the US pretreatment was reported to be more effective. The US pretreatment method led to accelerate the digestion process. In this project, oil refinery sludge with industrial feature attained to steady state after $41 \mathrm{~d}$; this resulted in a decline in anaerobic digester volume, and, in turn, it is presented as a method preventing from accumulation and disposal of dried sludge.

\section{Conclusions}

Recently, there have been increasing restrictions on water and wastewater treatment and studies research new measures having the lowest expenditure and advantages in terms of operating conditions for removal of organic matters from water and wastewater. The process of ultrasond irradiation in conjunction with anaerobic digestion has reached good results. In the current study, four combined reactors were utilized to survey the potential of treatability of oil refinery sludge. Anaerobic digestion of the sludge using with or without ultrasonic was introduced as an efficient method because the sludge was stabilized over $31 \mathrm{~d}$. The ratio of $\mathrm{COD} / \mathrm{BOD}_{5}$ decreased to $0.08-0.09$ at the end of the 41 th day. It shows that there has been an increase in the biodegradability of the sludge. In a steady state, the removal efficiency improved with increasing the time of irradiation. The bottom line is that ultrasound waves can reduce digestion time resulting in a decrease in the volume of anaerobic digesters and, in turn, costs.

\section{Conflicts of Interest}

This study did not have any conflict of interest statement.

\section{References}

Apul O.G. and Sanin F.D. (2010), Ultrasonic pretreatment and subsequent anaerobic digestion under different operational conditions, Bioresource technology, 101, 8984-8992.

APHA (2008), Standard method for the examination of water and wastewater, 19th ed. American Public Health Association, Washington, D.C.

Bougrier C., Albasi C., Delgenes J.-P. and Carrere H. (2006), Effect of ultrasonic, thermal and ozone pre-treatments on waste activated sludge solubilisation and anaerobic biodegradability, Chemical Engineering and Processing: Process Intensification, 45, 711-718.

Braguglia C., Gianico A. and Mininni G. (2012), Comparison between ozone and ultrasound disintegration on sludge anaerobic digestion, Journal of environmental management, 95, 139-143.

Cesaro A. and Belgiorno V. (2013), Sonolysis and ozonation as pretreatment for anaerobic digestion of solid organic waste, Ultrasonics sonochemistry, 20, 931-936.

Cheng C.-J. and Hong P.A. (2013), Anaerobic digestion of activated sludge after pressure-assisted ozonation, Bioresource technology, 142, 69-76.

Dewil R., Baeyens J. and Goutvrind R. (2006), Ultrasonic treatment of waste activated sludge, Environmental Progress, 25, 121-128.

Dhar B.R., Nakhla G. and Ray M.B. (2012), Techno-economic evaluation of ultrasound and thermal pretreatments for enhanced anaerobic digestion of municipal waste activated sludge, Waste Management, 32, 542-549.

El-hadj T.B., Dosta J., Marouez-Serrano R. and Mata-El-hadj J. (2007), Effect of ultrasound pretreatment in mesophilic and thermophilic anaerobic digestion with emphasis on naphthalene and pyrene removal, Water Research, 41, 87-94.

Erden G., Buyukkamaci N. and Filiblei A. (2010), Effect of low frequency ultrasound on anaerobic biodegradability of meat processing effluent, Desalination, 259, 223-227. 
Jin Y., Wang D. and Zhang D. (2015), Treatment of high - strength ammonia containing wastewater using partial nitritation system with biological selector, Global NEST Journal, 17(4), 738-743.

Kocyig H. and Ugurlu A. (2015), Biological decolorization of reactive Azo dye anarobic/aerobic sequencing batch reactor system, Global NEST Journal,17(1), 210-215.

Ma H., Zhang S., Lu X., Xi B., Guo X., Wang H. and Duan J. (2012), Excess sludge reduction using pilot-scale lysiscryptic growth system integrated ultrasonic/alkaline disintegration and hydrolysis/acidogenesis pretreatment, Bioresource technology, 116, 441-447.

Mistil T., Tezel U. and Pavlostathis S.G. (2013), Fate and effect of naphthenic acids on oil refinery activated sludge wastewater treatment systems, Water Research,47, 449-460.

Mohammadi A.R., Mehrdadi N., Bidhendil G.N. and Torabian A. (2011), Excess sludge reduction using ultrasonic waves in biological wastewater treatment, Desalination, 275, 67-73.

Muz M., Ak M.S., Komesli O.T. and Goksay C.F. (2014), Intermittent ozone application in aerobic sludge digestion, Ozone: Science \& Engineering, 36, 57-64.

Naddeo V., Cesaro A., Mantzavinos D., Fatta-Kassinos D. and Belgiorno V. (2014), Water and wastewater disinfection by ultrasond irradiation - A critical review, Global NEST Journal, 16, 561-577.

Nosrati M., Amano T. and Sreekrishnan T. (2011), Thermophilic anaerobic digestion of waste activated sludge versus mesophilic anaerobic digestion, International Conference on Advances in Biotechnology and Pharmaceutical Sciences, Bangkok Dec., 226-229.

Pilli S., Bhunia P., Yan S., Leblanc, R., Tyagi R. and Surampalli R. (2011), Ultrasonic pretreatment of sludge: a review, Ultrasonics sonochemistry, 18, 1-18.

Rahmani A.R., Nematollahi D., Godini K. and Azarian G. (2013), Continuous thickening of activated sludge by electroflotation, Separation and Purification Technology, 107, 166-171.

Rocha J.H.B., Gomes M.M.S., Fernandez N.S., Da Silva D.R. and Martinez-Huittle C.A. (2012), Application of electrochemical oxidation as alternative treatment of produced water generated by Brazilian petrochemical industry, Fuel Processing Technology, 96, 80-87.

Şahinkaya S. and Sevimli M.F. (2013), Sono-thermal pre-treatment of waste activated sludge before anaerobic digestion, Ultrasonics sonochemistry, 20, 587-594.

Şahinkaya S. and Sevimli M.F. (2013), Synergistic effects of sono-alkaline pretreatment on anaerobic biodegradability of waste activated sludge, Journal of Industrial and Engineering Chemistry, 19, 197-206.

Salsabi M.R., Laurent A.J., Casellas M. and Dagot C. (2010), Techno-economic evaluation of thermal treatment, ozonation and sonication for the reduction of wastewater biomass volume before aerobic or anaerobic digestion, Journal of Hazardous Materials, 174, 323-333.

Xie B., Liu H. and Yan Y. (2009), Improvement of the activity of anaerobic sludge by low-intensity ultrasound, Journal of Environmental Management, 90, 260-264. 